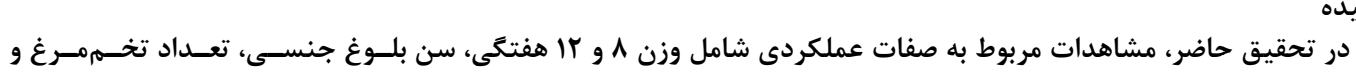

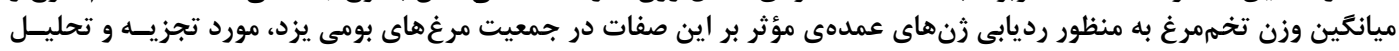

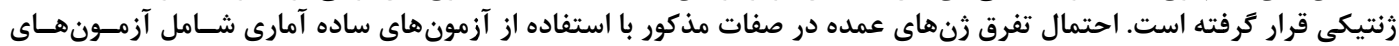

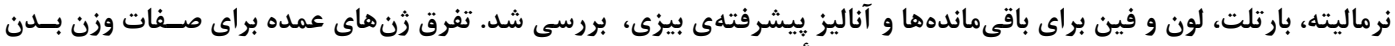

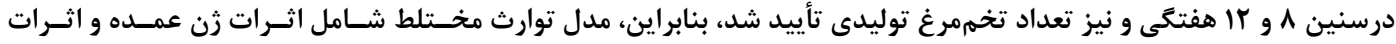

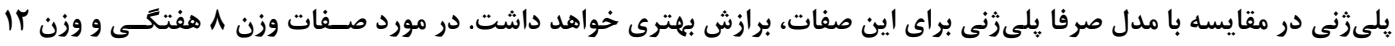

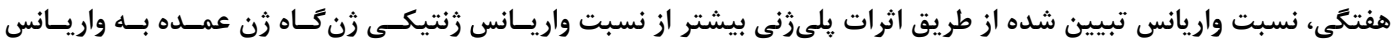

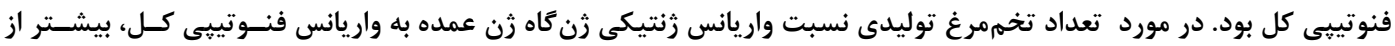

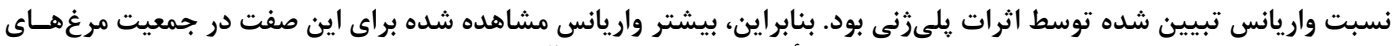

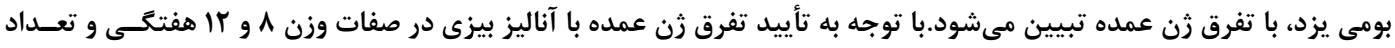

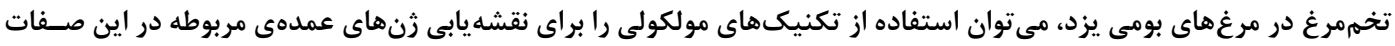

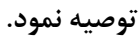

وازههاى كليدى: آناليز بيزى، تفرق زن عمده، آزمون بارتلت، توارث مختلط، مرغهاى بومى

صفات كيفيت تخممرغ مانند ضخامت يوسته، مقاومت

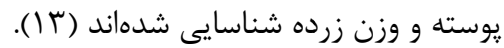

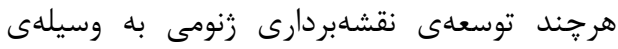

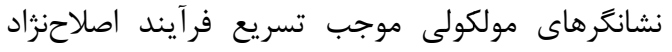

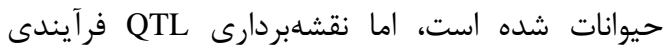

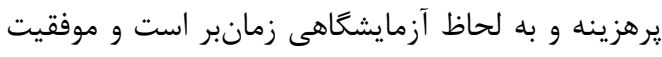

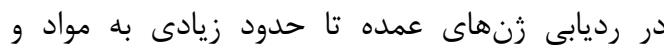

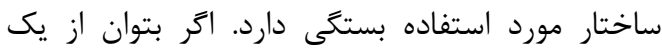

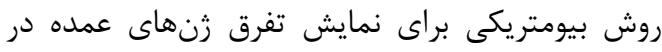

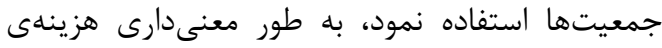

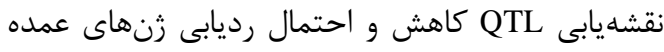

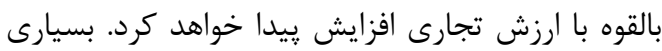

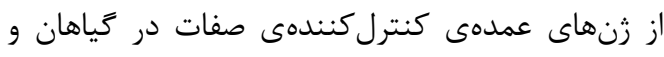

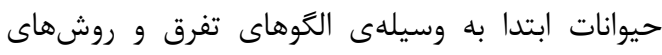

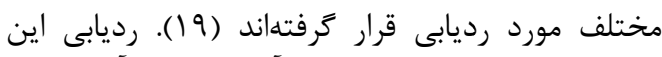

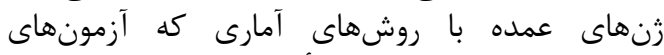

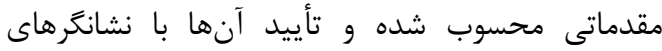

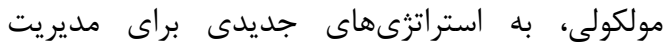

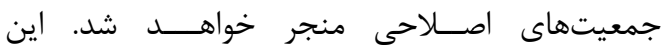

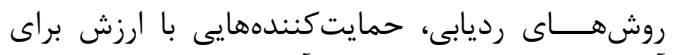

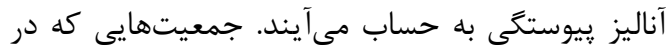
1- Quantitative trait loci

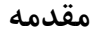

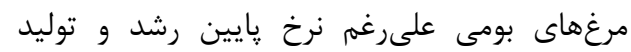

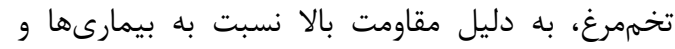

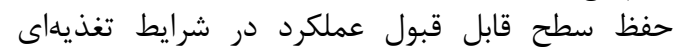

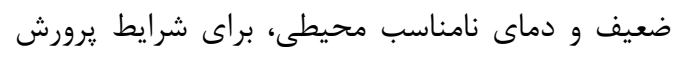

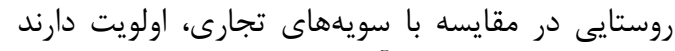

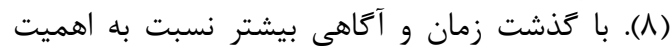

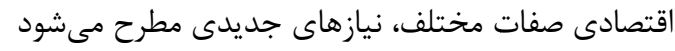

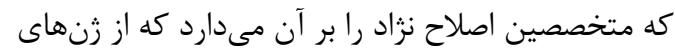

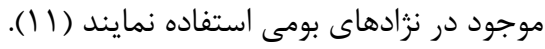

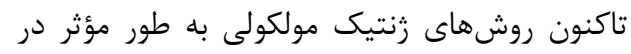

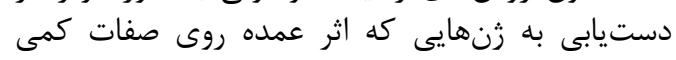

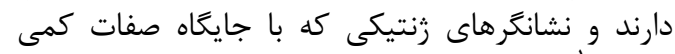

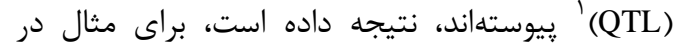

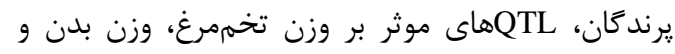

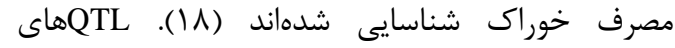
متعددى نيز در ارتباط با صفات ظوفئ ظاهرى، سلامتى،

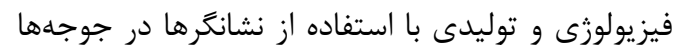

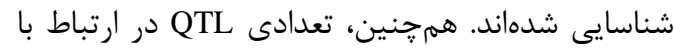

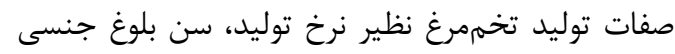

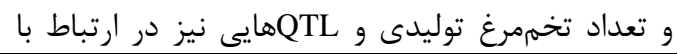




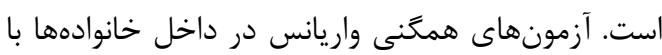
آزمونهاى بارتلت و لون و ون نرمافزار

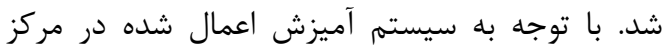

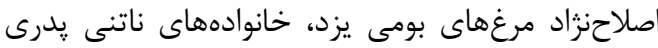

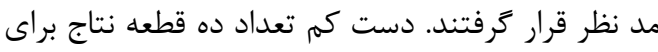

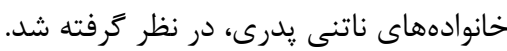

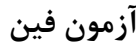

خانوادههاى با تفرق زن عمده يعنى با حداقل يك آلين

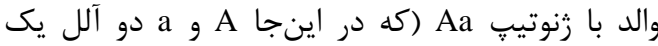

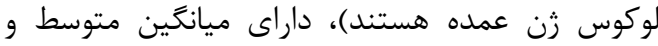

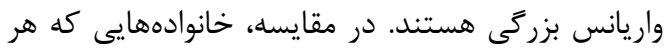

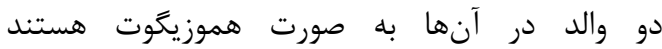

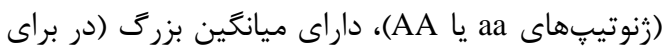

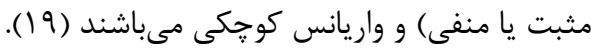

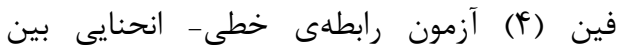

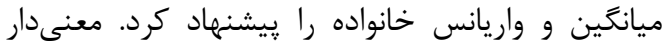
بودن ضريب درجهى دوم در اين رابن رابطه نشانهاى از از وجود

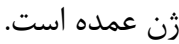

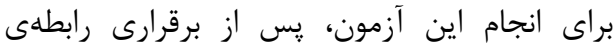

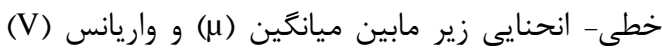

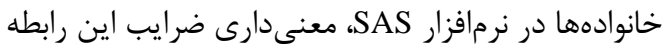
$\mathrm{V}=\mathrm{b}_{0}+\mathrm{b}_{1}+\mathrm{b}_{2}^{2}$

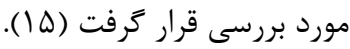

در اين رابطه V نشاندهندهى واريانس داخل

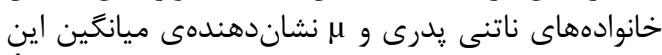

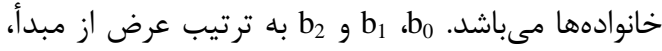

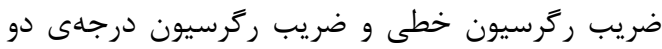

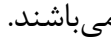
روش آناليز تفرق بيزى إن إن إن

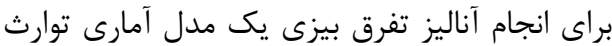

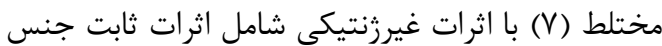

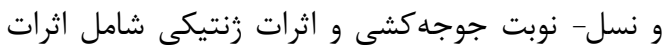

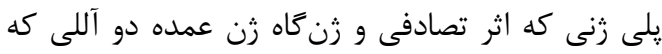

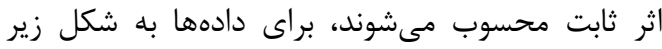

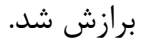

$y=X b+Z a+Z W m+e$

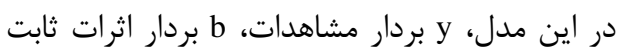

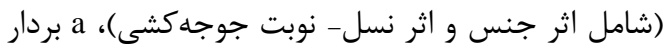

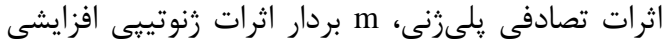

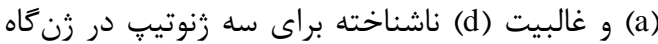

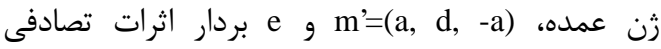
باقىمانده است. ماتريسهاى X و X

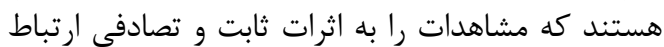

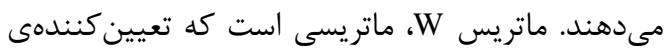

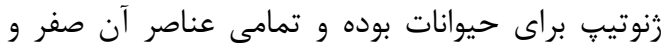
يك مىباشند، بلهورى كه در در هر رديف رئ اين ماتريس
آنها تفرق زن عمده رديابى نمىشود ممكن است آتي

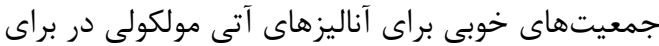

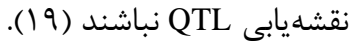
براى شناسايى زنهاى عمده و وتخمين اثرات آندات آنها

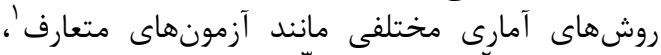

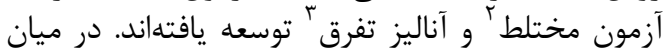

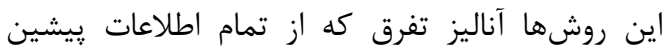

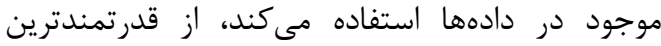

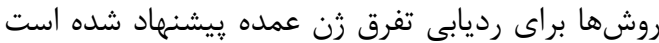

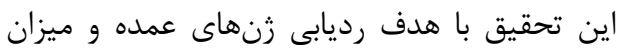

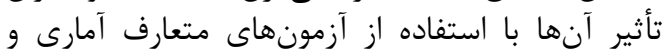

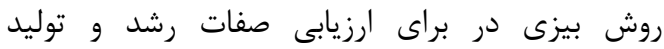
تخممرغ جمعيت مرغهاى بومى استان ارئ يزفات يزد، انجام شده ترليد

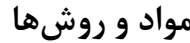

دادهاى مورد استفاده در اين تحقيق، مربوط بـ به به

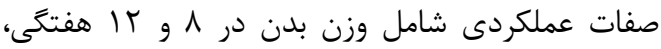

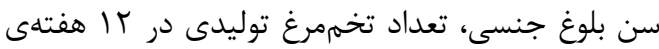

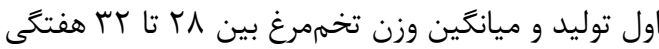

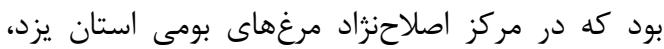

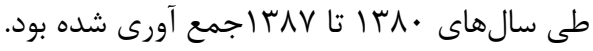

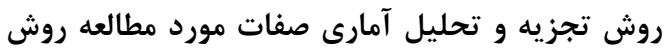

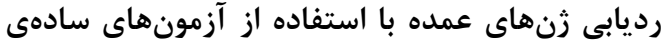

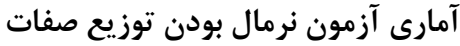

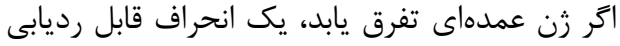

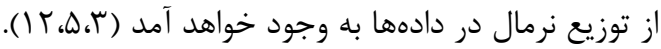

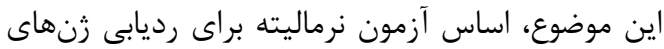

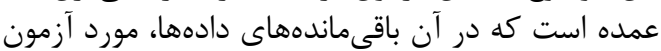

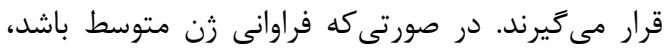

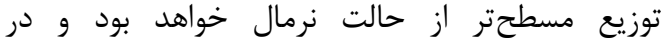

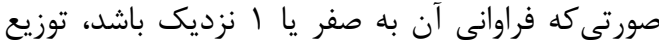

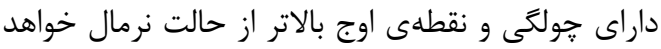

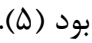

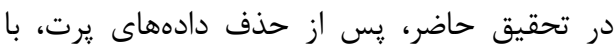

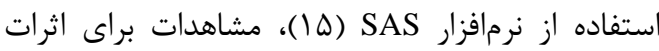

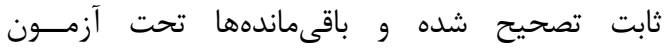

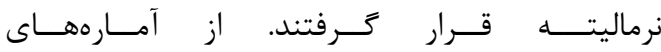
Cramer-von Mises ،Kolmogorov-Smirnov(K-S) Anderson-Darling (A-D) و براى اين منظور (C-vM) استفاده شد.

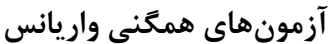

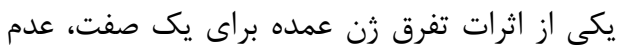

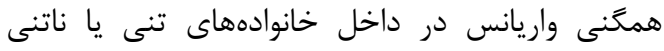

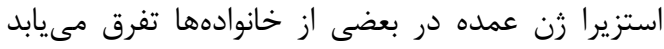
Test Segregation Analysis 


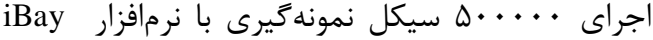

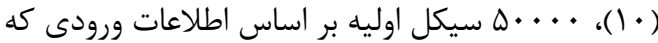

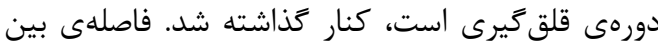

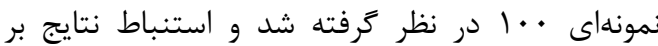

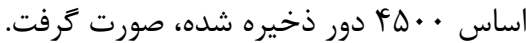

\section{نتايج و بحث} نتايج رديابى زنهاى عمده باد با آزمونهاى ساده

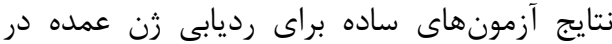

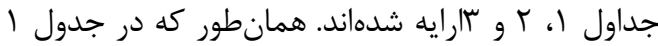

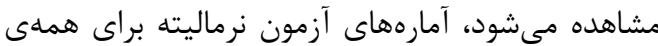

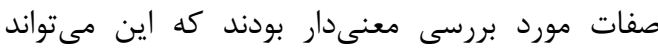
علامت اوليهى تفرق زن عمده در اين صفات در درد نظر

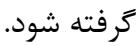

تنها يك مقدار برابر با يك وجود دارد و مابقى صفر

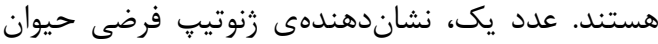

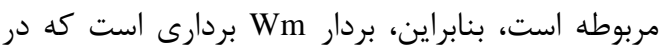

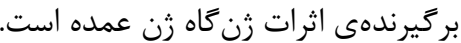

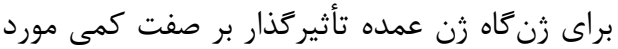

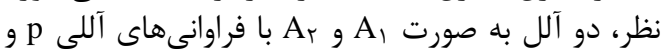

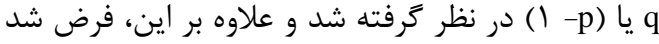

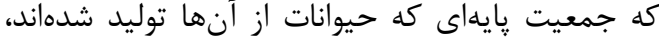

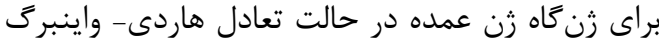

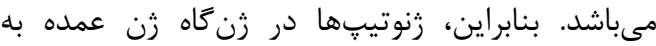
صورت

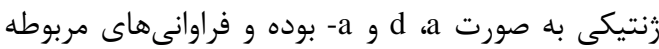

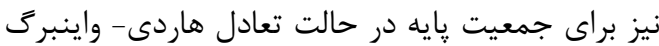

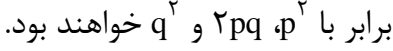
با مفروضات ذكر شده در آناليز تفرق بيزى، يس از

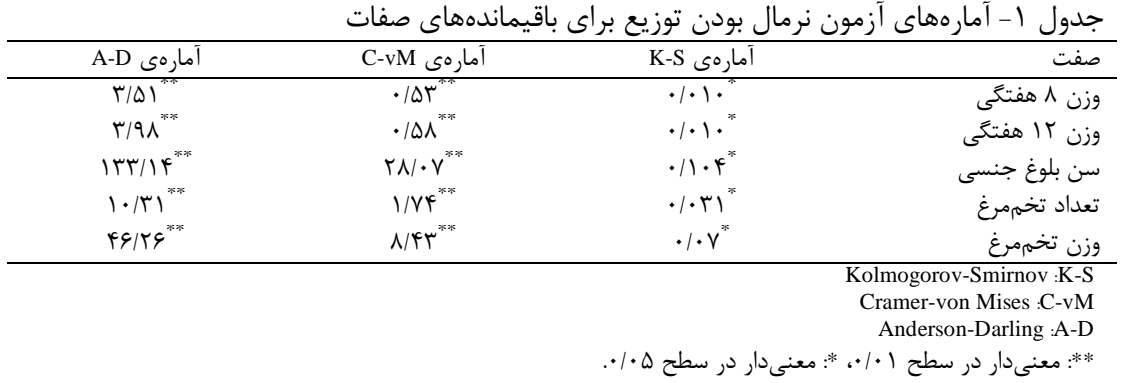

باشد. اما در حالت تفرق زنهاى عمده، بسته به زنوتيتٍ

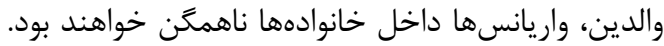

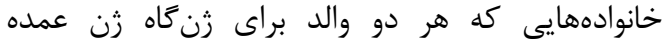

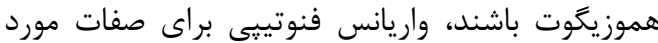

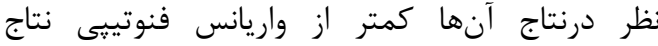

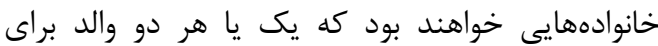

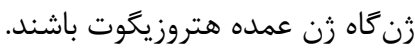

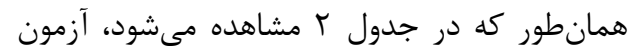

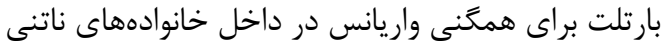

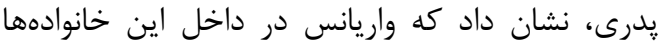

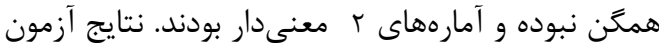

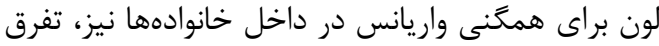

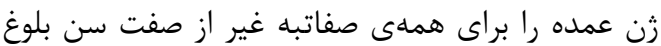

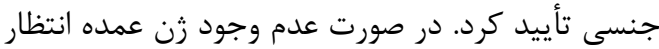
مىرود واريانس داخل خانوادههاى ناتنى يدرى هرد همثن

\begin{tabular}{|c|c|c|}
\hline آزمون لون & همخگنى واريان & صفتول r- نتايج \\
\hline $1 / 10^{n}$ & $f / Y / D^{\text {Tath }}$ & وزن \ هفتگىى \\
\hline $1 / \Lambda r^{n \uparrow r}$ & $\Delta V V / q^{n+n}$ & وزن rا هفتگى \\
\hline$q / \Delta r^{\mathrm{ns}}$ & $|V| N / \Delta^{\circ}$ & سن بلوغ جنسى \\
\hline 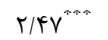 & $991 / 9^{m-\pi}$ & تعداد تخممرغ \\
\hline$\Delta / \Gamma V^{\pi \omega \pi}$ & & وزن تخممرغ \\
\hline
\end{tabular}

صفات با آزمون فين تأييد شد. در رابطهى با صفت تعداد

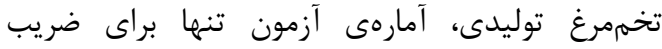

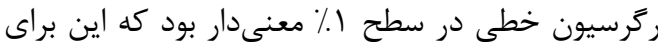

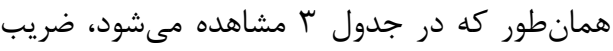

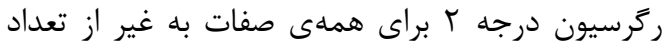

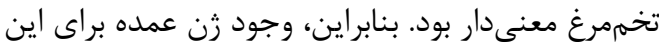




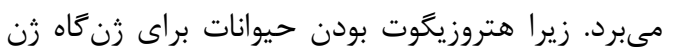

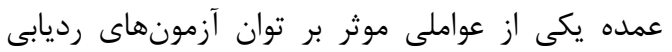

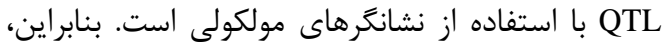
مى توان از نتايج آزمون فين در اين رانئ رابطه استفاده نمود

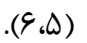

تأييد وجود زن عمده با آزمون فين كافى نيست. انتخاب

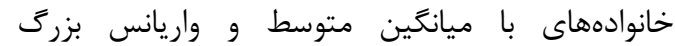

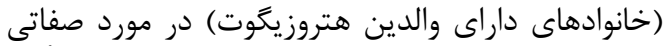

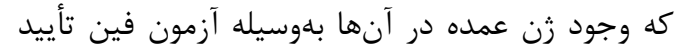

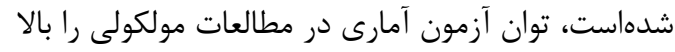

\begin{tabular}{|c|c|c|}
\hline درجه r & خطى & صفت \\
\hline $1 / \Lambda r^{\prime \prime}$ & $-\cdot / 11^{\mathrm{ns}}$ & وزن 1 هفتگى \\
\hline $1 / 9 V^{*}$ & $\cdot / r \Delta^{\mathrm{ns}}$ & وزن | ال هفتتىى \\
\hline $9 / \Lambda^{* * \pi *}$ & $r / \Delta \Delta^{*}$ & سن بلوغ جنسى \\
\hline $1 / \cdot 1^{\mathrm{ns}}$ & $T / V V^{* *}$ & تعداد تخممرغ \\
\hline$\Delta / f \varphi^{n \cdots \uparrow}$ & $r / 99^{n+n}$ & وزن تخممرغ \\
\hline
\end{tabular}

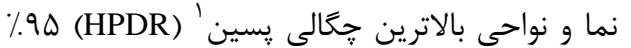

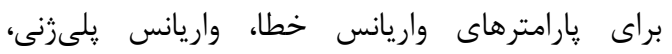

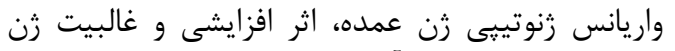

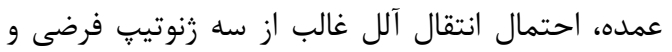

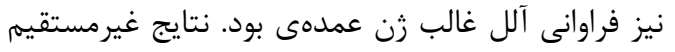

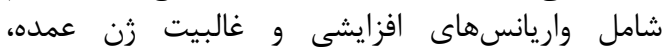

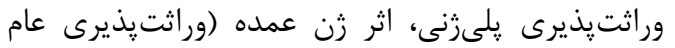

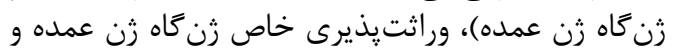

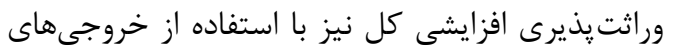

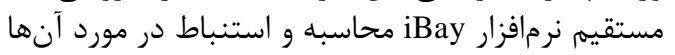

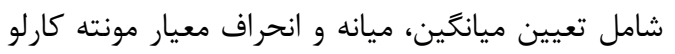

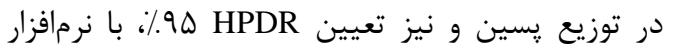
PostGibbs

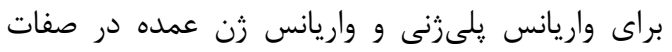
عملكردى در جدول ب ارايه شدهاست.
به طور كلى، نتايج آزمونهاى ساده تا حدود زيادى ئري

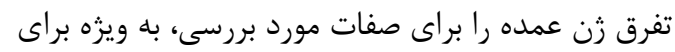

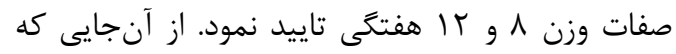

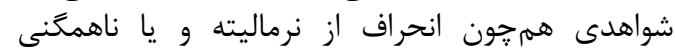

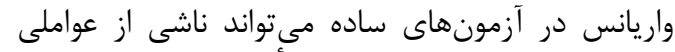

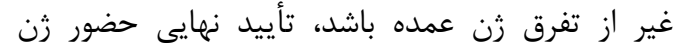
عمده و تعيين ميزان اثر آن به آناليز تفرق يِيجيده نياز

دارد. - ماره

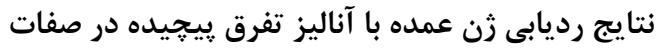

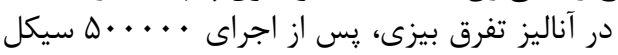

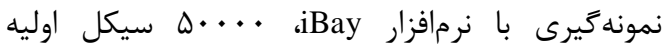

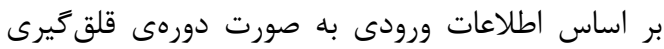

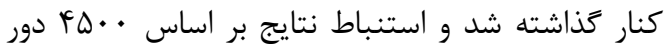

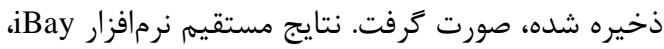

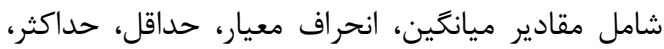

\begin{tabular}{|c|c|c|c|c|}
\hline \multicolumn{2}{|c|}{ واريانس زن عمده } & \multicolumn{2}{|c|}{ واريانس يلىزنى } & \multirow[b]{2}{*}{ صفت } \\
\hline HPD Left & HPD Right & HPD Left & HPD Right & \\
\hline$T V \cdot / \Lambda$ & $1.991 . \mathrm{T}$ & $911 / \pi$ & $1 r \cdot N / 9$ & وزن 1 هفتگى \\
\hline VIFAV/D & $\mu F V \Delta / F$ & TVYFq/Q & rQTा/r & وزن ا ا هفتگىى \\
\hline$\cdot /$. & IVG/AV & $\Delta / V r$ & $r \cdot / / f$ & سن بلوغ جنسى \\
\hline Tr/Tr & $\mid \Lambda F / \Lambda$ & - /A 9 & $4 / 99$ & تعداد تخممرغ \\
\hline.$/$. & $T / 9 V$ & $.1 . \mathrm{f}$ & .199 & وزن تخممرغ \\
\hline
\end{tabular}

در حالى است كه در تحقيق سدلوزكى و سازوسكى

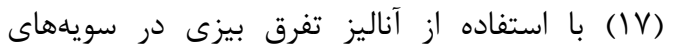

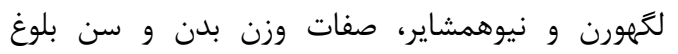

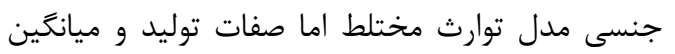

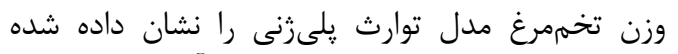

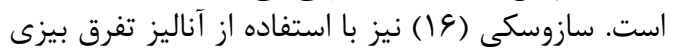

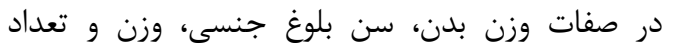
تخممرغ توليدى، زنهاى عمدهاى را در لائ لاين تخمثذار 1- Highest Posterior Density Regions

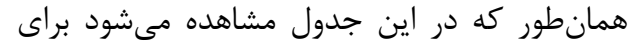

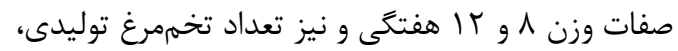

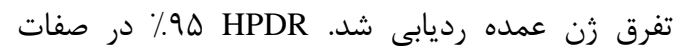

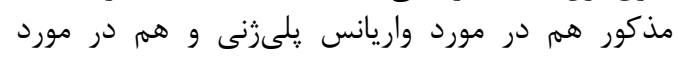

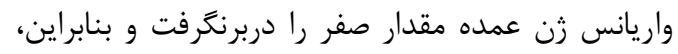

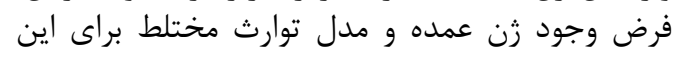

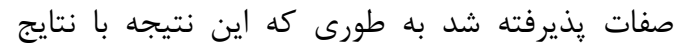
آزمونهاى ساده در مورد اين صفات مطابقت دارئ دارد اين اين 
خصوصيات توزيعهاى بسين براى برخى پارامترهاى

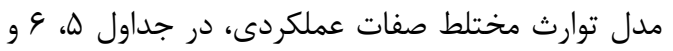

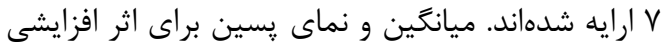

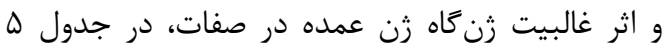
نشان داده شدهاست.

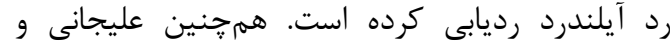

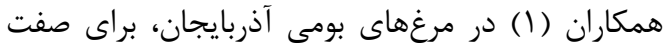

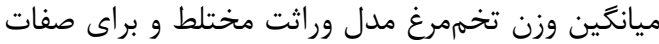

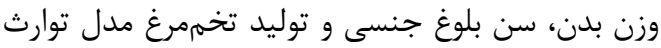

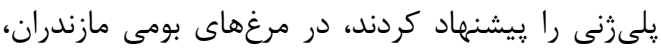

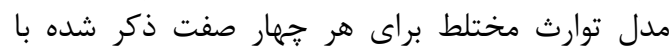
استفاده از آناليز تفرق بيزى تأييد شد.

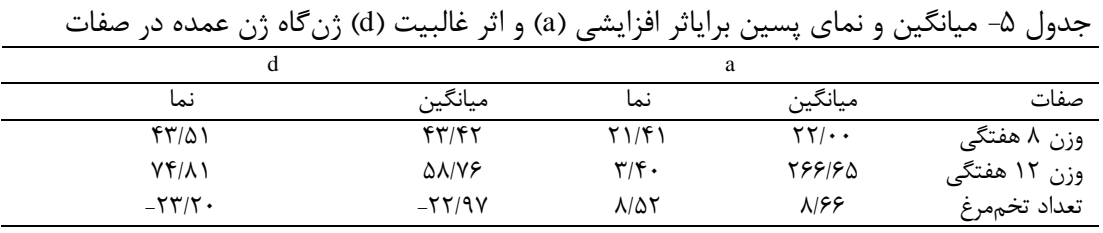

مغلوب (1-p) براى اين زن به دمست آمدند و واريانس

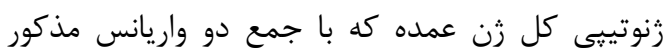

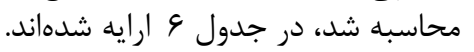

واريانس افزايشى و غالبيت زن عمده كه با استفاده

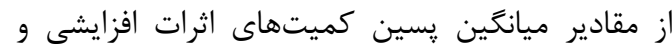

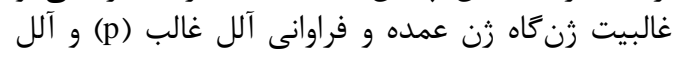

\begin{tabular}{|c|c|c|c|}
\hline $\mathrm{v}_{\mathrm{T}}$ & $\mathrm{v}_{\mathrm{d}}$ & $\mathrm{v}_{\mathrm{a}}$ & صفات \\
\hline TRT/AV & $9 / V T$ & $r / f / l f$ & وزن 1 هفتتى \\
\hline T\$9/90 & $r / V V$ & TET/AV & وزن ا I هفتخىى \\
\hline$\Delta Q / T V$ & $F \Delta / Y \Lambda$ & १/१८ & تعداد تخممرغ \\
\hline
\end{tabular}

نسبت واريانس كل زن عمده به واريانس فنوتييى

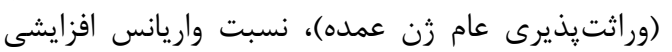

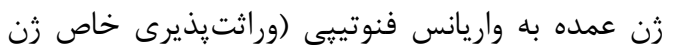

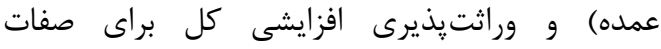
عملكردى در جدول Vارايه شدهاند.

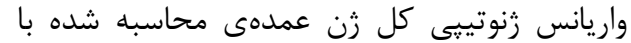

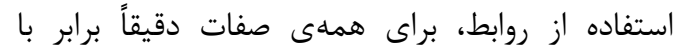

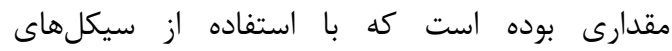

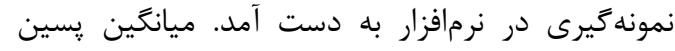

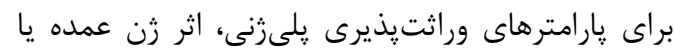

\begin{tabular}{|c|c|c|c|c|}
\hline $\mathrm{h}_{\mathrm{T}}^{2}$ & $\mathrm{~h}_{\mathrm{m}}^{2}$ & $\mathrm{R}_{\mathrm{m}}$ & $\mathrm{h}_{\mathrm{p}}^{2}$ & صفات \\
\hline$\cdot / T \Lambda$ & $\cdot / \cdot \Delta T$ & $\cdot / \cdot \Delta \Delta$ & . & وزن ^ هفتتى \\
\hline rז/. &.$/ \cdot r$. & ./. I & $\cdot / r \cdot 4$ & وزن rا هفتگكى \\
\hline.$/ 191$ & $\cdot / \mu \wedge$ & $\cdot 19 \cdot V$ &.$/ . \mu$. & تعداد تخممرغ \\
\hline
\end{tabular}

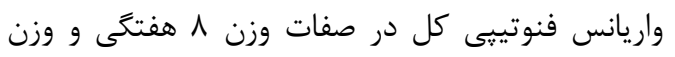

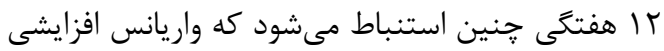

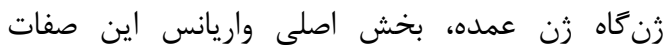

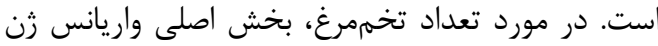

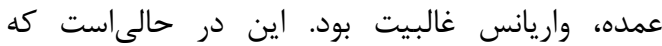

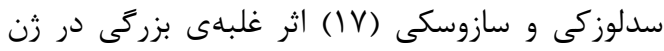

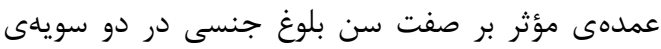
لكمهورن و نيوهمشاير رديابى نمودند.

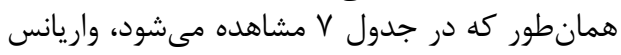

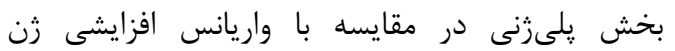

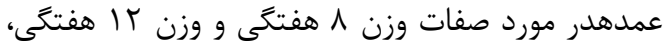
تعيين كنندهتر است. عليجانى و همكاران (1) نيز وزئ درن

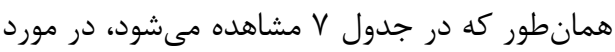

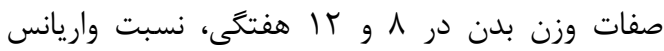

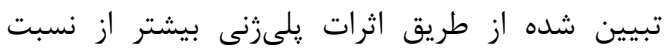

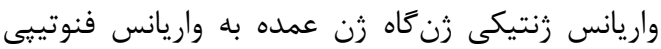

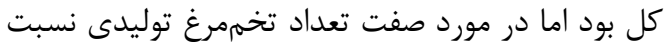

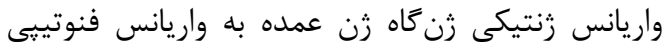

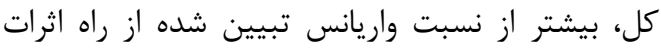

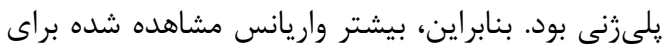

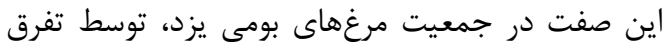

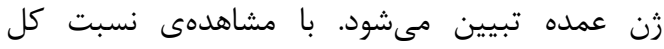

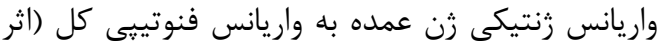
زن عمده) و نسبت واريانس افزايشى اين زن رناه 
حاشيهاى پسين براى وراثتيذيرى يلىثنى و اثر زن عمده ر انشان مى دهد.
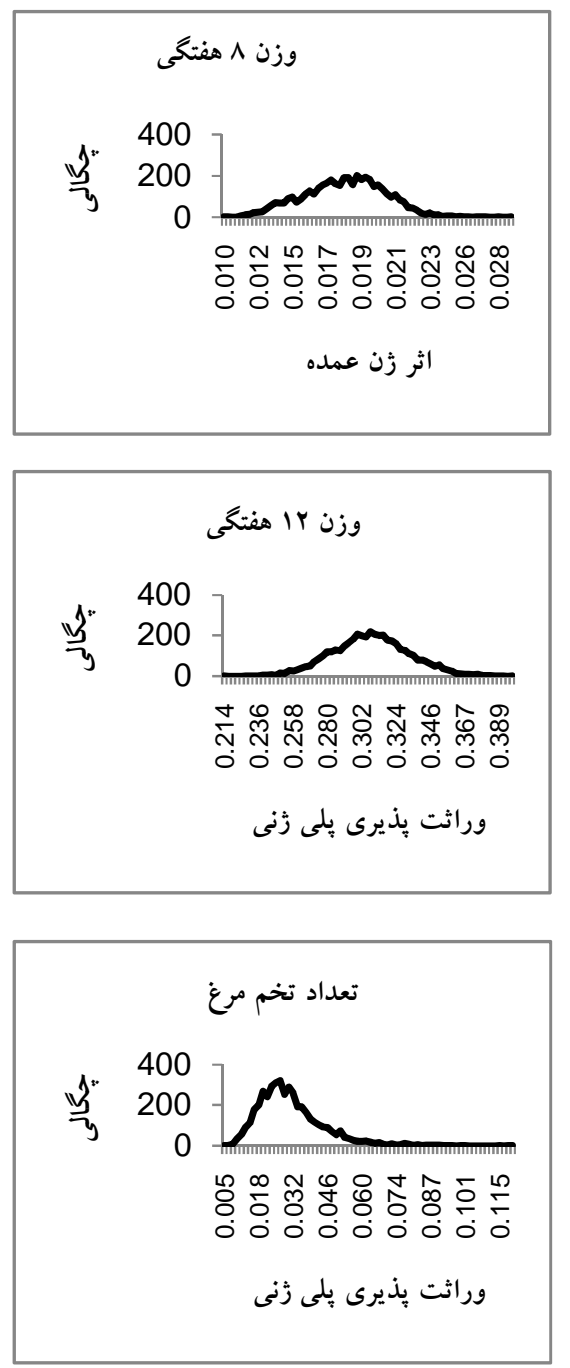

شكل ا- توزيعهاى حاشيهاى يسين براى وراثتيذيرى يلىزنى و اثر زن عمدهى رديابى شده در صفات وزن

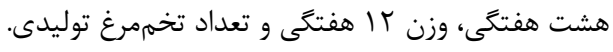

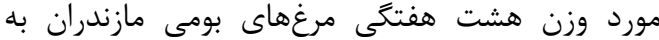
نتيجهى مشابهى دست يافتند. شكل إنى توزيعهاى
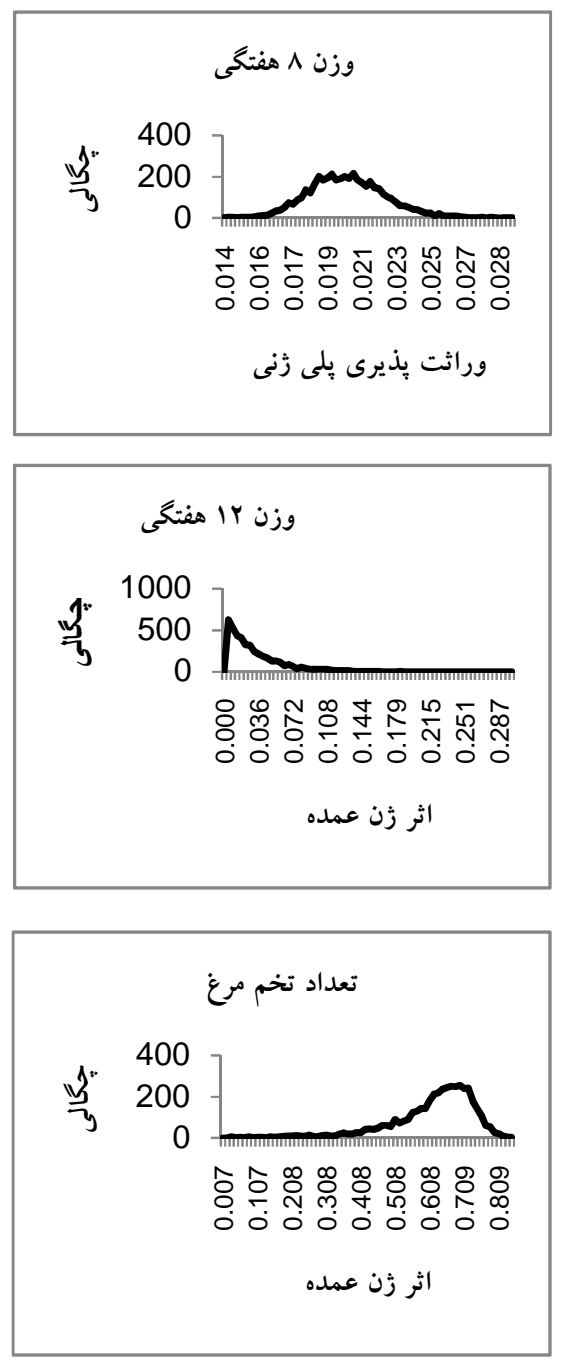

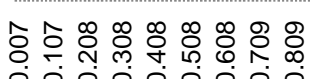
اثر زن عمده
مدل صرفاً يلىزنى، براى دادههاى صفات مذكور در اين

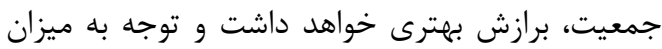

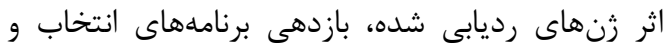

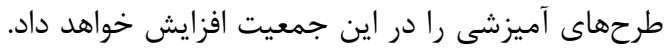

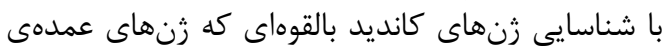

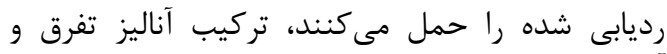

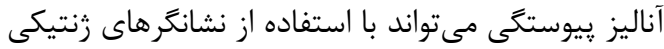

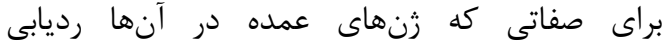
شده است، انجام گيرد.
نتايج رديابى زنهاى عمده به تاريخجهى اصلاحنزاد

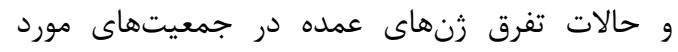

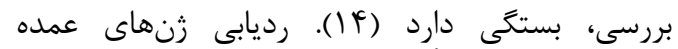

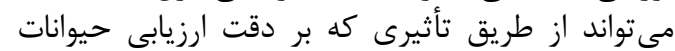

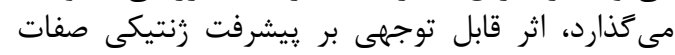

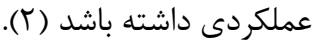

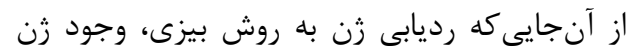

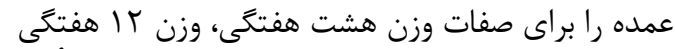

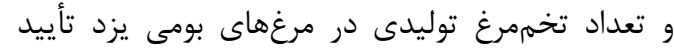
نمود، به نظر مىرسد مدل توارث مختلط در در مقايسه باد بادي 
Alijani, S., H. Yegane Mehrabani, A. Nejati Javaremi, G. Rahimi and L.L.G. Janss. 2010. Bayesian segregation analysis to detect major genes influencing four economically important traits in two Iranian native pedigreed chickens. The $10^{\text {th }}$ Iranian Statistical Conference. University of Tabriz.

2. Argente, M.J., A. Blasco, J.A. Ortega, C.S. Haley and P.M. Visscher. 2003. Analysis for the presence of major gene affecting uterine capacity in unilaterally ovariectomized rabbits. Genetics, 163: 10611068.

3. Cemal, I. 1996. Major genes in farm animals: their identification, transfer and industrial utilization. M.Sc. Thesis (in Turkish).YuzuncuYil University. Van. Turkey. 79 pp.

4. Fain, P.R. 1978. Characteristics of simple sib-ship variance tests for the detection of major loci and application to height, weight and spatial performance. Annals of Human Genetics, 42: 109-120.

5. Falconer, D.S. and T.F.C. Mackay. 1996. Introduction to Quantitative Genetics. $4^{\text {th }}$ Edition. London, Longman. $465 \mathrm{pp}$.

6. Hill, W.G. and S. Knott. 1990. Identification of gene with large effects. In: Advances In statistical methods for genetic improvement of livestock. Springer-verlag. Berlin, 517-538.

7. Hofer, A. and B.W. Kennedy. 1993. Genetic evaluation for a quantitative trait controlled by polygenes and a major locus with genotypes not or only partly known. Genetic Selection Evolution, 25: 537-555.

8. Horst, P. 1989. Native fowls as reservoir for genomes and major genes with direct and indirect effect on the adaptability and their potential for tropically oriented breeding plans. Archiv fur Geflugelkunde, 53: 93-101.

9. Ilahi, H. and H.N. Kadarmideen. 2004. Bayesian segregation analysis of milk flow in Swiss dairy cattle using Gibbs sampling. Genetic Selection Evolution, 36: 563-576.

10. Janss, L.L.G. 2007. iBay manual version 1.33. http://www.lucjanss.com/ Docs/iBayManual133.pdf.

11. Kianimanesh, H.R., A. NejatiJavaremi and M. Kamali. 2002. Estimation of genetic and environmental parameters of Fars Native Fowl. Journal ofPajooheshvaSazandegi, 5: 6-9 (In Persian).

12. Le Roy, P. and J.M. Elsen. 1992. Simple test statistics for major gene detection: a numerical comparison. Theoretical and Applied Genetics, 83: 635-644.

13. Liu, W., D. Li, J. Liu, S. Chen, L. Qu, J. Zheng, G. Xu and N. Yang. 2011. A genome-wide SNP scan revealsnovelloci for egg production and quality traits in White Leghorn and brown-eggdwarflayers, PLoS One, 6: e28600.

14. Ochiai, A., T. Ishida, K. Oyama and F. Mukai. 2005. Trial for detecting carriers with major genes in a selected layer line. Animal Science Journal, 76: 195-201.

15. SAS Institute. 2001. SAS/STAT User's Guide: Statistics. Release 8.2. SAS InstituteInc., Cary, NC.

16. Szwaczkowski, T. 1993. Identification of major animal genes in field collected data by use of statistical methods. A review. Journal of Animal and Feed Sciences, 2: 91-103.

17. Szydlowski, M. and T. Szwaczkowski. 2001. Bayesian segregation analysis of production traits in two strains of laying chickens. Poultry Science, 80: 125-131.

18. Tuiskula-Haavisto, M. 2004. Quantitative trait loci for eggquality and production in layinghens. Agri food Research Reports, 60 pp.

19. Zeng, W. 2000. Statistical methods for detecting major genes of quantitative traits using phenotypic data of diallel mating. Ph.D. Thesis, North Carolina State University Raleigh, USA. 145 pp. 


\title{
Detecting Major Genes for Some Economic Traits in Native Fowl of Yazd Province using Different Statistical Methods
}

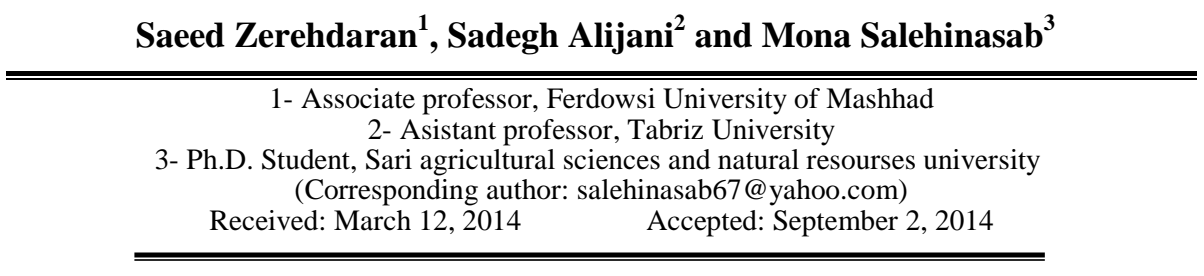

\begin{abstract}
At the present study, the observations of performance traits including body weight at 8 and 12 weeks of age, age at sexual maturity, egg weight and egg number were analyzed to detect major genes in Yazd native fowl. The probability of segregation for major genes was studied using simple tests including tests of normality, Bartlett, Levene and Fain for residuals and Bayesian analysis. Segregation of major genes was only confirmed for body weight at 8 and 12 weeks of age and egg number. Therefore, based on these results, mixed inheritance model including major gene and polygenic effects is better compared to absolute polygenic model for these traits. Although for body weight at 8 and 12 weeks of age, polygenic effects variance was more than major gene variance, the reverse was true for egg number. Therefore, the main observed variance for this trait is created by major genes effect. Confirmation of major genes segregation for body weight and egg number in Yazd native fowl demonstrates that molecular techniques can be suggested to map the related major genes.
\end{abstract}

Keywords: Bayesian analysis, Bartlett test, Major gene segregation, Mixed inheritance, Native fowl 